\title{
Community-Driven Development in Afghanistan
}

\author{
A Case Study of the National Solidarity Programme in Wardak
}

\begin{abstract}
This article assesses the legacy of the National Solidarity Programme in seven districts of Wardak Province, Afghanistan. We find that the NSP largely achieved its development objectives, but had limited effects on state-society relations. The findings also raise questions about the sustainability of community-driven development in insecure contexts.
\end{abstract}

KEYWORDS: Afghanistan, Wardak, governance, aid, insurgency

\section{INTRODUCTION}

Governments and donor agencies have increasingly relied on communitybased approaches to deliver development assistance in developing countries, including in a large number of fragile and conflict-affected states. ${ }^{1}$ In contrast to a development-spending model driven by centralized decision-making, community-driven development (CDD) devolves some control of decisionmaking and resources to local councils. By giving local communities a voice in identifying development priorities and providing a mechanism to engage

Jasmine Bhatia is a Postdoctoral Research Fellow at the School of Oriental and African Studies, University of London. Naseem Jareer is a Research Team Leader at ATR Consulting, Kabul, Afghanistan. Ross McIntosh is a Monitoring and Evaluation Specialist at ATR Consulting. This study was generously funded by the Swedish Committee for Afghanistan. Emails: <jbro6@soas. ac.uk>, <naseem.jareer@atr-consulting.com>, <rossalexmcintosh@googlemail.com>.

I. Philippe Dongier, Julie Van Domelen, Elinor Ostrom, Andrea Ryan, Wendy Wakeman, Anthony Bebbington, Sabina Alkire, Talib Esmail, and Margatet Polski, "Community Driven Development," World Bank Poverty Reduction Strategy Paper, 2003; Haider Huma, "CommunityBased Approaches to Peacebuilding in Conflict-Affected and Fragile Contexts," University of Birmingham, 2009; Sheree Bennett and Alyoscia D'Onofrio, "Community-Driven Development in Conflict-Affected Contexts: Revisiting Concepts, Functions and Fundamentals," Stability: International Journal of Security and Development 4:I (2015).

Asian Survey, Vol. 58, Number 6, pp. I042-I065. ISSN ooo4-4687, electronic ISSN 1533-838X. (C) 2018 by The Regents of the University of California. All rights reserved. Please direct all requests for permission to photocopy or reproduce article content through the University of California Press's Reprints and Permissions web page, http://www.ucpress.edu/journals.php?p=reprints. DOI: https:// doi.org/Io.I525/AS.20I8.58.6.I042. 
with local government on the provision of public services, advocates believe that CDD programs result in better decisions on development spending, greater legitimacy and accountability of the government to its citizens, and more opportunities for vulnerable or oppressed groups to participate in local politics. ${ }^{2}$ In areas under threat from insurgent groups, aid projects have often been touted as a potential counter-insurgency tool, rewarding communities under government control and preventing at-risk communities from defecting to insurgents.

This paper challenges some core assumptions of this approach. We explore the legacy of the National Solidarity Programme (NSP), a flagship CDD program in Afghanistan, with an in-depth case study of the program's impact in Wardak, a province under severe threat by insurgents. To date, very few studies have explored how CDD programs function in highly insecure contexts; hence, very little is known about how nascent local institutions developed under CDD adapt to conditions of deteriorating security. Wardak, a relatively dangerous province with a significant degree of insurgent activity, provides opportunities to observe how resilient these institutions are in areas where government control is strongly contested. Also, while most existing evaluations of CDD have measured short- to medium-term impacts, this study provides insights on how the NSP has functioned from its inception in 2003 until the end of 2016.

While we find that the NSP functioned as a relatively effective mechanism for aid delivery, there is little evidence that it delivered transformative institutional changes in the long run or significantly improved local perceptions of the government. Instead, in most cases local councils set up under the NSP became active only during periods when they received NSP project funding, and remained dormant at other times. Generally, they played a role in other governance activities only insofar as local council members overlapped with other customary institutions. Rather than seeing themselves as affiliated with the state, local council members in insecure areas were often highly critical of the government and saw themselves as institutionally distinct, in some cases openly collaborating with insurgents instead. Finally, we found that in more conservative areas, institutional guidelines mandating the inclusion of women in decision-making were rarely followed. These findings challenge some of the theoretical assumptions underpinning CDD in insecure 
contexts, and suggest methodological improvements for how these programs should be evaluated.

The findings presented here are based on approximately 70 interviews with community members in seven districts in Wardak, additional interviews with government and NGO service delivery providers, and three community mapping exercises illuminating local power dynamics and governance mechanisms. This article proceeds as follows. The next section outlines the theoretical mechanisms of CDD and reviews the literature on the utility of this approach in conflict-affected areas. The third section provides background on the NSP, with a particular focus on the program's activities in Wardak. The fourth section outlines the study's approach and methodology. The fifth presents our results with respect to development and institutional outcomes. We conclude by discussing theoretical and practical implications for future CDD programs in Afghanistan and elsewhere.

\section{THEORETICAL FRAMEWORK: COMMUNITY-DRIVEN DEVELOPMENT IN VIOLENT CONTEXTS}

An ongoing debate in the political violence literature has concerned the relative merits of "greed" versus "grievance" explanations for civil conflict. One body of research has found a robust statistical link between poor economic conditions-especially widespread poverty-and violence. ${ }^{3}$ Another school argues that conflict is primarily driven by local grievances against the government, which are particularly exacerbated by perceived inequalities between groups. ${ }^{4}$

Though not an approach designed solely for violent contexts, CDD addresses aspects of both of these drivers of conflict. CDD is underpinned by two theoretical logics. ${ }^{5}$ The first concerns how CDD functions as

3. Paul Collier and Anke Hoeffler, "Greed and Grievance in Civil War," Oxford Economic Papers 56:4 (2004); James D. Fearon and David D. Laitin, "Ethnicity, Insurgency, and Civil War," American Political Science Review 97:I (2003).

4. Gudrun Østby, "Polarization, Horizontal Inequalities and Violent Civil Conflict," Journal of Peace Research 45:2 (2008): I43-62; Lars-Erik Cederman, Nils B. Weidmann, and Kristian Skrede Gleditsch, "Horizontal Inequalities and Ethnonationalist Civil War: A Global Comparison," American Political Science Review I05:3 (201I): 478-95.

5. Bennett and D'Onofrio ("Community-Driven Development") describe these logics slightly differently in a three-logic framework: welfare, governance, and social cohesion. We have opted for the two-logic framework above as closest in spirit to how informants we interviewed conceptualized it. 
a mechanism to improve local development outcomes. Because it gives communities more control over how public resources are spent, CDD advocates believe that it is a more efficient method of reducing poverty than other modalities. Consistent with the literature on the virtues of bottom-up development, it holds that local residents have a better understanding of their environment and needs than state planners, and stronger incentives to reduce corruption and ensure that public goods are delivered as intended. ${ }^{6}$ Moreover, community members are often actively involved in constructing development projects through the provision of local goods or labor, and thus receive additional economic benefits.

The second logic concerns the potential of CDD as a state-building tool to precipitate transformative institutional changes. These transformations are sometimes categorized as having both bonding and bridging effects. ${ }^{7}$ Bonding effects typically refer to fostering more trust and inclusiveness in local communities. CDD programs work by establishing, training, and empowering elected bodies in rural communities to plan and implement development projects. By strengthening these bodies and giving them resources to distribute in their communities, proponents believe, CDD programs create receptive ground for democratic governance. ${ }^{8}$ Programs usually include some participatory mandate for inclusiveness, ensuring representation of women and other marginalized groups, and thus reducing the risk of unequal public goods distribution. ${ }^{9}$ Having achieved a measure of credibility through public goods delivery, local councils are expected to eventually expand into other areas of governance typically reserved for informal customary institutions, such as dispute resolution. ${ }^{10}$

Bridging effects refer to building trust between the central government and local communities, fast-tracking the process of formal institution-building. Extending formal state institutions in rural communities is often an expensive and laborious process that may take decades, especially for governments with

6. Susan Wong and Scott Guggenheim, "Community-Driven Development: Myths and Realities,” World Bank Policy Research Working Paper 8435, 2018.

7. Howard White, Radhika Menon, and Hugh Waddington, "Community-Driven Development: Does It Build Social Cohesion or Infrastructure? A Mixed-Method Evidence Synthesis," International Initiative for Impact Evaluation, 2018.

8. Wong and Guggenheim, "Community-Driven Development."

9. White, Menon, and Waddington, "Community-Driven Development."

Io. Ashraf Ghani and Clare Lockhart, Fixing Failed States: A Framework for Rebuilding a Fractured World (Oxford University Press, 2009). 
limited capacity. Creating local councils through CDD programs is an alternative means of establishing a presence in local communities and rapidly demonstrating goodwill through the delivery of public goods. Once established, councils are intended to serve as a bridge between the government and local communities, providing information about community needs and acting as an engagement hub for government line ministries.

Though distinct, this logic closely aligns with the counter-insurgency literature focused on winning "hearts and minds" in contested areas. This doctrine is rooted in the belief that the support of the population is a critical resource, particularly in discouraging cooperation with opposition groups and providing the government vital intelligence on insurgent activities. Advocates of this approach argue that good governance, primarily through public goods provision, is a primary mechanism for building government legitimacy and securing local allegiance. ${ }^{11}$ Community-driven programs that improve public goods provision may therefore improve the standing of the government in local communities, potentially dampening insurgent activities.

While these assumptions have underpinned development and counterinsurgency efforts in unstable regions of the world for the past two decades, until recently there was little empirical evidence about their validity. In recent years, a burgeoning literature has emerged testing these theoretical logics, including a number of large-scale evaluations in countries affected by political violence. Results have been mixed. Panel evidence collected over a four-year period in Iraq suggests that the provision of public goods in local areas did have a positive effect on perceptions of the government and led to significant reductions in violence. ${ }^{12}$ Another study found that local community development projects in Afghanistan were well regarded by the public, but aid was least effective-and often destabilizing — in areas where large amounts of money were spent quickly, creating resentment between communities and ample opportunities for extensive corruption. ${ }^{13}$

II. For a detailed model linking public service provision to reduced insurgent violence, see Eli Berman, Jacob N. Shapiro, and Joseph H. Felter, "Can Hearts and Minds Be Bought? The Economics of Counterinsurgency in Iraq," Journal of Political Economy II9:4 (20II): 766-819.

I2. Ibid.

13. Paul Fishstein and Andrew Wilder, "Winning Hearts and Minds? Examining the Relationship between Aid and Security in Afghanistan," Feinstein International Center, Tufts University, 2012. 
Evaluations that have focused on how CDD programs function in violent contexts have produced no clear consensus to date. A randomized field experiment testing the performance of the NSP in Afghanistan (an initiative that supports community development councils in local towns and villages to provide input on how development assistance is spent) found that the program led to a significant improvement in villagers' perception of their own economic well-being and their attitudes to the government. ${ }^{14}$ However, a study summarizing evidence from multiple similar field experiments in sub-Saharan Africa found that results were often negligible and that programs supporting participatory councils did not bring lasting improvement in social cohesion..$^{15}$ More recently, a review of 25 impact evaluations of CDD programs around the world found that, while CDD programs were generally effective at producing small-scale infrastructure, they had little to no impact on improving governance or social cohesion. ${ }^{16}$ Another literature review of nearly 500 participatory programs also found little evidence that participatory interventions led to long-lasting improvements in group cohesion, but noted that they performed better than top-down government programs at delivering higher-quality public goods with less corruption. ${ }^{17}$

Case studies at the subnational level have suggested areas where more theoretical sophistication is needed. With regard to the NSP, multiple studies have noted that acceptance of elected councils and their role in local governance varies from community to community, including how council members engage with customary elites. ${ }^{18}$ The degree to which community development councils function as intended is contingent on a number of factors that are neglected in existing theories, particularly the nature of preexisting communal institutions and practices. ${ }^{19}$ The longevity of CDD

I4. Andrew Beath, Fotini Christia, and Ruben Enikolopov, "Winning Hearts and Minds through Development Aid: Evidence from a Field Experiment in Afghanistan," Working Paper 166, Centre for Economic and Financial Research, New Economic School, 20II.

I5. Elisabeth King, Cyrus Samii, and Birte Snilstveit, "Interventions to Promote Social Cohesion in Sub-Saharan Africa," Journal of Development Effectiveness 2:3 (2010).

I6. White, Menon, and Waddington, "Community-Driven Development."

17. Ghazala Mansuri and Vijayendra Rao, Localizing Development: Does Participation Work? World Bank, 2012.

18. H. Nixon, "The Changing Face of Local Governance? Community Development Councils in Afghanistan," Afghanistan Research and Evaluation Unit, 2008; A. Pain, "Using Village Context Analysis in Afghanistan: Methods and Wider Implications," Working Paper 47, Secure Livelihoods Research Consortium, London, 2016.

19. Pain, ibid. 
programs is another underexplored variable. An early study on the sustainability of local councils set up under the NSP raised concerns that the councils would likely wither away without sustained project funding, but few studies have explored to what extent this has actually happened. ${ }^{20}$

Despite the accumulated evidence on CDD in conflict-affected countries, there are significant gaps in the literature. Evaluation methodologies often measure impacts in the short-to-medium term. For example, a randomized control trial on the NSP covered a four-year period from the baseline to the endline. ${ }^{21} \mathrm{~A}$ recent review found that, of all known evaluations of CDD programs worldwide, the longest available at the time of writing covered a period of seven years. ${ }^{22}$ At present, there are very limited data on how CDD programs fare in the long term.

Also, although a number of evaluations have been completed in conflictaffected countries, data are often collected from relatively secure areas within those contexts. The randomized NSP study above, for example, excluded districts from the most insecure southern provinces of Afghanistan. ${ }^{23}$ The lack of evidence on how CDD programs operate in insecure contexts represents a major lacuna in current theoretical frameworks. While existing theories of change may treat insurgencies as an exogenous factor, there is ample evidence that once violent conflicts begin, local dynamics change in fundamental and often unpredictable ways. These can have significant effects on how CDD programs operate and are received in beneficiary communities. ${ }^{24}$ It is likely that a modified set of theoretical expectations is appropriate for these contexts.

This study is a step toward addressing these gaps. We examine the legacy of the NSP from 2003 to late 2016 in a province that has had an active insurgency since 2006. Many of the villages profiled have received multiple rounds of NSP funding, and local councils have been operating for a decade or longer. The findings provide a rare window into how CDD programs

20. Jennifer Brick, "Investigating the Sustainability of Community Development Councils in Afghanistan," Afghanistan Research and Evaluation Unit, Kabul, 2008.

2I. Andrew Beath, Fotini Christia, and Ruben Enikolopov, "Empowering Women through Development Aid: Evidence from a Field Experiment in Afghanistan," American Political Science Review I07:3 (2013): 540-57.

22. Wong and Guggenheim, "Community-Driven Development," 24.

23. Beath, Christia, and Enikolopov, "Empowering Women."

24. For an authoritative account of these dynamics, see Stathis N. Kalyvas, The Logic of Violence in Civil War (Cambridge University Press, 2006). 
operate in terms of both developmental and institutional logics in such an environment, and how these logics are impacted by the active presence of insurgent groups.

\section{THE NATIONAL SOLIDARITY PROGRAMME}

\section{History and Structure of the NSP}

Costing over US $\$ 2$ billion between 2003 and 2016 , the NSP was perhaps the single largest and most far-reaching development assistance program in Afghanistan's history. ${ }^{25}$ It was funded by several international donors and managed by the Afghan Ministry of Rural Rehabilitation and Development with some technical support from donors and international consultancy firms. While security problems prevented the NSP from being delivered in every community in Afghanistan, it was implemented widely, spanning approximately 35,000 rural communities in all 34 of Afghanistan's provinces. The program commenced in 2003 and closed in early 2017, replaced by a follow-up program called the Citizens' Charter.

The NSP was delivered in three phases. The core elements of project design remained consistent for all these phases, though minor adjustments to policies and procedures were made over the years. Phase I ran from May 2003 to March 2007, reaching approximately 17,300 communities. Phase II ran from April 2007 to September 20II, targeting an additional 6,00o communities. Phase III ran from November 20II to March 20I7, adding a further 13,500 communities. In addition to expanding into new communities, Phase II and Phase III also provided repeat grants to some beneficiaries from earlier phases to be used for new projects.

In each village, the program rolled out as follows. At the outset, community mobilizers employed by facilitating partners-typically local or international NGOs affiliated with the NSP-approached the village to introduce the program. Next, they facilitated local elections, in which each adult individual in a community voted by secret ballot for candidates to form a community development council (CDC). Once the council was established, the NSP gave its members capacity-building training to equip them with the skills to assess and manage development projects. The

25. World Bank, "Community-Driven Development," <http://www.worldbank.org/en/topic/ communitydrivendevelopment>, accessed July I8, 2018. 
community was allocated $\$ 200$ per household by the Afghan government, to be disbursed by the CDC on small pre-selected infrastructure development projects. The CDCs selected either a project with a budget ceiling of the combined household allocation for the village, or $\$ 60$, ooo for villages with more than 300 households. Once approved, the project was constructed, usually with the help of the NGO facilitating partners. The villages themselves were also required to contribute 1o $\%$ of the project cost in cash, materials, or labor. Some CDCs received more than one block grant in subsequent rounds of the NSP.

From the beginning, the Afghan government and the donor community had more-ambitious aspirations for the program. The NSP stipulated that CDC leadership include an equal number of men and women, a significant break from traditional rules concerning the role of women in local governance. In addition to its role as a mechanism to deliver public goods, the NSP was conceived as a means to transform governance in local communities, providing a formal alternative to customary structures. Ashraf Ghani, then minister of finance and one of the main architects of the NSP, saw the elected CDCs as an antidote to traditional patronage-based politics and the influence of local commanders. Although the CDCs formally existed in parallel with customary structures, Ghani believed that the CDCs could expand their mandate considerably:

Having gathered the necessary institutional and social capital and demonstrated its usefulness in the creation of infrastructure and services ... [the NSP] is now ready to become the platform for a more ambitious series of undertakings at the village level. It could, for instance, easily supervise the construction of schools, clinics, and small dams, undertake agricultural extension services, or become a mechanism for the registration and formalization of property rights and dispute resolution at the village level. ${ }^{26}$

Beyond managing the NSP block grants, the CDCs were intended to act as a mechanism with which government line ministries and NGOs could coordinate to implement other public services and development projects in the community. While the CDCs were tasked with improving community welfare through infrastructure and local development, the long-term goal of institution-building was therefore fundamental to the design and 
assumptions underpinning the program. For at least a decade, the Afghan government has been considering proposals to give CDCs some type of formal institutional recognition, embedding them within existing state hierarchies. ${ }^{27}$ This paper assesses how developmental and institutional logics have fared in the province of Wardak, where the NSP has been implemented since 2003 .

\section{WARDAK AND THE NATIONAL SOLIDARITY PROGRAMME}

Wardak is an exceptionally challenging development context. It is a predominantly agrarian society, and the vast majority of its roughly half a million inhabitants live in rural areas. ${ }^{28}$ It ranks below the national average on poverty, literacy, access to health services, and school attendance, particularly for girls. ${ }^{29}$ Due to its strategic location just west of Kabul, the province has experienced heavy fighting since 2006, and territory is heavily contested by government forces and opposition groups. Wardak is frequently classified as one of the most insecure provinces in Afghanistan, and has one of the highest rates of internally displaced persons in the country. ${ }^{30}$

Insecurity has gradually escalated in Wardak since the mid-20oos, with the government losing control of territory over time. Wardak is about $35 \mathrm{~km}$ from Kabul, making it a useful base for attacks on the capital. ${ }^{31}$ The province lies along a key transportation link, the main highway between Kabul and the southern provinces of Ghazni and Kandahar. A second important road runs from the provincial capital of Maydan Shah to the central highlands of Bamiyan. The strategic importance of this province has led to intense ongoing conflict between insurgents and government forces. ${ }^{32}$

There are nine administrative districts in Wardak. Interviews were conducted in seven of them: Markazi Behsud (Behsud I), Hesi-e Awali Behsud

27. Nixon, "Changing Face of Local Governance."

28. World Bank, Afghanistan Provincial Briefs 20I6, <http://www.worldbank.org/en/country/ afghanistan/publication/afghanistan-provincial-briefs-20I6>, accessed August 26, 2018.

29. Ibid.

3o. European Asylum Support Office, "EASO Country of Origin Information Report: Afghanistan Security Situation, January 20I6," <https:/www.easo.europa.eu/sites/default/files/public/ EASO-COI-Afghanistan_Security_Situation-BZo4I6ooIENN_FVI.pdf>, accessed August 26, 2018.

3I. Ibid.

32. Ibid. 
(Behsud II), Jalrez, Maydan Shah, Nerkh, Sayd Abad, and Jaghatu. ${ }^{33}$ At the time that the research was conducted, security conditions varied considerably in the districts of interest. The two northwestern districts, Behsud I and II, were relatively secure. These districts, linking the central highlands to the Kabul-Kandahar corridor, have higher concentrations of ethnic Hazaras, and insurgent activity is relatively low. However, these provinces have experienced an ongoing and ethnically charged conflict between Pashtun nomads and local Hazara residents regarding grazing rights. ${ }^{34}$

The other districts covered by the study have serious security issues. The Afghan government controls only the main roads running through these districts, while the Taliban has a widespread presence in rural areas. Nerkh, in the east of the province, has experienced fighting between insurgent group Hezb-i-Islami [literally, Islamic Party] and the Taliban, with both groups also engaged in combat operations against the government. Maydan Shah, the district containing the provincial capital, is controlled by the government within city limits and along the main roads in and out of Kabul, but is otherwise strongly contested by insurgents. Multiple local security reports collected during fieldwork suggest that government officials rarely travel outside Maydan Shah.

In spite of the poor security situation, the NSP was widely implemented in Wardak. In the seven districts where the research took place, CDCs implemented at least 2,563 projects. ${ }^{35}$ Irrigation and transport accounted for more than $50 \%$ of these, though there was considerable variation across districts. The most frequently selected type of project in Behsud II, Jaghatu, and Jalrez was irrigation, such as the improvement of irrigation canals and the maintenance of karez (traditional irrigation) systems. Electrification projects were more commonly selected by CDCs in Maydan Shah, Nerkh, and Sayd Abad. These projects included the purchase of generators and the installation of micro-hydropower systems to provide electricity to homes near running water. Transportation projects, principally road and bridge construction, were most frequently selected in mountainous Behsud I. Because the NSP

33. The other two districts, Chaki Wardak and Day Mirdad, were inaccessible during the fieldwork period.

34. LandInfo, "Afghanistan: The Conflict between Hazaras and Kuchis in the Behsud Districts of Wardak Province,” 20II, <http://www.landinfo.no/asset/2057/I/2057I.pdf>, accessed July 24, 2018.

35. Data provided by the Swedish Committee for Afghanistan. 
has remained active in the context of widespread insecurity, Wardak offers a unique opportunity to study how dynamics of CDD are affected by insurgent violence.

\section{APPROACH AND METHODOLOGY}

Before starting key informant interviews with beneficiaries, nine preliminary interviews were completed with government officials and donors who worked on the NSP between 2003 and 2016. The purpose of these interviews was to understand more about the background and institutional context of the NSP, as well as specific challenges in the province of Wardak. These interviews were conducted in November 2016.

Out of a total of 909 villages that had received NSP funding, we selected one in each of the seven target districts. Villages in each district were selected from the full list of settlements that had received the NSP, with inaccessible villages removed beforehand. ${ }^{36}$ We classified the remaining settlements according to the different categories of development projects undertaken (irrigation, electrification, etc.), and then consulted local security experts in selecting individual sampling points that captured a variety of these categories while ensuring the safety of the research team. In each selected village, trained enumerators conducted in-depth semi-structured interviews with adult men, women, and CDC members. Enumerators were instructed to interview community members from a variety of socioeconomic backgrounds in the village and to sample from marginalized groups in particular. The socioeconomic background of respondents was determined by a subjective judgment by enumerators based on a combination of factors (education, occupation, quality of home and assets, social status in the village, etc.). Fieldwork was conducted in November and December 2016.

One month after the first round of fieldwork was completed, a series of community mapping exercises was conducted in a second round of qualitative field research in Nerkh, Behsud I, and Jaghatu. The exercises were conducted by phone with community members who were initially contacted during the in-person first round of fieldwork. The interviews aimed to

36. Given the sensitive nature of the questions and that fact that some respondents might be identifiable by their positions, we do not reveal the names of the villages. In the rest of the paper we refer to each location by its district name only. 
validate initial findings and insights from the first round of interviews and to collect additional information on the local political situation and community dynamics.

Given that large areas of the province are under insurgent control, we acknowledge that a limitation of this study is that field researchers could only visit villages with a minimum level of accessibility. Providing safe access to target communities was our greatest challenge, especially for female field researchers. Women have very restricted mobility in Wardak, and it is difficult for them to travel from district to district without attracting attention. Because we removed inaccessible villages in each district from the list of potential sampling points, the remaining villages are generally located in areas with more security, typically closer to the main roads. The findings are therefore not necessarily representative of conditions in the province as a whole. But almost all areas of Wardak are significantly affected by insecurity, and interviewees in almost all districts frequently cited security as a major concern. It is likely that our findings apply even more strongly in the most insecure areas. We therefore hold that, despite limitations on the fieldwork, the study provides valuable insights on the dynamics of CDD programs in insecure contexts.

\section{RESULTS}

We examined the legacy of the NSP in the target communities in terms of both developmental and institutional logics. The developmental logic explores how effective local councils were as a mechanism for delivering public goods and enhancing economic welfare, examining their record on project delivery and contributions to economic well-being across all socioeconomic groups. The institutional logic is concerned with the transformational aspects of CDD: the extent to which local councils became involved in responsibilities typically reserved for customary institutions, broadened participation in local decision-making, and built lasting links between communities and the state resilient to challenges from insurgent groups.

\section{Developmental Logic: Delivery of Public Goods}

Overall, we found strong evidence that the NSP had contributed to the development of public goods in the form of local infrastructure, resulting 
in tangible economic benefits for community members. Respondents confirmed that most of their CDC's selected projects had been constructed, and there were few indications that planned infrastructure projects had been abandoned. Community members in the target areas generally had a positive perception of the infrastructure produced under the NSP and a strong appreciation for the program in general.

In Jaghatu, for example, the local CDC allocated most of its resources to a single infrastructure project: the construction and extension of an irrigation canal. ${ }^{37}$ Community members reported that this canal is still widely used for irrigation. They generally judged the canal to be of good quality, though two respondents mentioned that they needed further funds for maintenance. They also reported that the installation of the canal has allowed people to create new farmland in previously unused areas, as the supply of water to these areas has expanded. Some respondents claimed that the project has principally benefited those who own the extended farmland, though they noted that others use the water from the canal as a source of drinking water.

In Jalrez, by contrast, the CDC opted to construct a number of smaller projects, including deep wells, a road, a water supply network, and solar electricity. Locals complained that the first project, a well, was a poorly constructed failure, but reported that other projects are still frequently used. Interviewees confirmed that the road made it easier for community members to travel, providing better access to health clinics and neighboring communities. One community member praised the NSP for improving the water supply network: "The NSP brought positive changes.... People now take water from the water supply system. They are happy. They used to use a donkey to fetch water but now they have it inside their homes." ${ }^{38}$

NSP infrastructure projects were positively associated with economic benefits by most respondents. When asked to identify specific economic benefits created by the NSP, respondents in most villages identified two major impacts. First, in communities where irrigation projects were undertaken, landowners who benefited from improved water systems reported that they had become wealthier as a direct result of the program. Furthermore, respondents

37. Data indicate it was started around 2010, but we could find no record of when it was completed.

38. Interview, driver from Jalrez District, December 8, 2016. 
in areas where roads were constructed reported an improvement in access to markets, clinics, and other public services in the district centers.

Another widely reported economic benefit was opportunities for temporary paid work during the construction period. Though these opportunities were not long-lasting, it is notable that many respondents, particularly the poorer ones, emphasized the positive economic impact of these short-term jobs for their households over other economic benefits. "The project benefited us economically because when we were constructing the water reservoir, the people who were unemployed received an income for the construction work," said one housewife from Behsud I. ${ }^{39}$ Two farmers from Behsud II also related that they personally received wages while working on NSP construction projects. ${ }^{40}$

Respondents identified a few problems with distribution of funds through the NSP. While respondents in most communities felt that economic benefits were distributed relatively equally, a small minority (about $16 \%$ ) felt that projects benefited certain community members more than others. Generally, this feeling was more common among lower-income respondents, particularly those living further from infrastructure projects. As one laborer in Behsud II put it: "All the people have had economic benefits [from the projects], but not me. I am in a very bad economic situation. Our economic situation was not good before, and it is still not good. My land does not have any crops. We are still poor people." ${ }^{41}$

Another problem associated with some public goods delivered through the NSP was a lack of sustainability. In Sayd Abad and Maydan Shah there were complaints about electrical generators installed through the NSP that were no longer operational due to a lack of planning to pay for fuel and maintenance, a common criticism from most interviewees from these areas. As one community member in Sayd Abad recalled:

The first [NSP] project was an electricity program. Every house was responsible for putting in money to operate the generator, and it worked for five years. After that, people couldn't afford to buy fuel for the generator or to repair the machine due to our economic conditions. So now the generator is 
not functioning. People are only benefiting from the bridge and the culvert, not the electricity project. ${ }^{42}$

Similarly, in Behsud II community members unanimously complained about a school project that was started in Phase I of the NSP but never finished, leaving the community with no usable educational facility. Indeed, respondents seemed to dwell on cases where projects had been started and failed or fallen into disrepair, indicating that raising public expectations for service delivery and subsequently failing to deliver may produce strong negative reactions in terms of public goodwill.

Nonetheless, these failures were relatively rare; most public goods undertaken in the seven villages were completed as planned and still operational. The findings from these seven villages suggest that the NSP in Wardak was indeed successful in achieving positive development outcomes, most of which appear to be durable in the medium term. While four of the seven villages reported that the NSP had delivered a piece of infrastructure that was either incomplete or no longer in use, all villages were using at least some of the infrastructure delivered through the program. It is also evident that the public goods built through the CDCs are considered useful and needed by community members, and that they have at least in some cases delivered tangible economic benefits. Notably, all respondents interviewed were aware of the NSP and could accurately identify something it had delivered, suggesting that the NSP was a relatively effective and successful mechanism for delivering public goods in the target communities.

\section{Institutional Logic: Transforming Local Governance}

The findings above suggest that the NSP has performed relatively well at delivering developmental objectives, and that villagers are aware of its role in bringing public goods into their communities. However, we found much weaker evidence that these successes have translated into the kinds of institutional transformations expected, in terms of both bridging and bonding effects. We found few indications that the establishment of the CDCs has substantively altered the local dynamics of authority. Furthermore, insecurity has become a significant obstacle, in some cases leading to a complete break between community leaders and state institutions. 


\section{Roles and Responsibilities of CDCs in Local Communities}

In the communities visited, the CDCs are seen primarily as a mechanism for the delivery of the NSP's infrastructure projects. When asked whether they had contacted the CDCs to ask for assistance, community members almost exclusively mentioned that they had done so to request new development projects. There was little sense from the interviews that communities expected the CDCs to play other governance roles or provide any other kinds of services.

Interviews with community members and CDC leaders provided few examples of the CDCs resolving low-level disputes in the community, which are instead addressed by customary authorities. In Behsud II, for example, one respondent stated that "the CDC doesn't resolve conflicts. The local shura [assembly] works on this issue." ${ }^{\text {43 }}$ While some CDC members told field researchers that they had taken part in resolving disputes, it was not a result of their position as a CDC member per se, but because of their parallel roles in community shuras or other customary structures. Where the CDC members are local elders, as in most of the communities visited for this study, the CDC and customary forms of governance are essentially interchangeable. According to one farmer in Jalrez, "The tribal elders and the CDC intervene [in disputes] because the CDC members are also the tribal elders." ${ }^{44}$ Another CDC member in Jaghatu agreed: "In fact, it is the responsibility of our malik [chief] to resolve local disputes, though I also take part. ... Just a short time ago a Pashtun girl escaped with a Hazara boy, and then the malik went and freed that girl and brought her back from Kabul to her family." ${ }^{45}$

NSP experts interviewed for this project confirmed this finding. While dispute resolution was not envisaged as the initial function of the CDCs, it was expected that, as trust with the community grew, they would gradually take on additional local governance roles, including dispute resolution. Instead, it appears that, at least in Wardak, customary institutions have continued to be the principal fora through which local disputes are resolved. In contested areas with a strong Taliban presence, the Taliban itself is a far more significant provider of justice and dispute resolution than the CDCs.

43. Interview, community member from Behsud II District, December 5, 2016.

44. Interview, driver from Jalrez District, December 8, 2016.

45. Interview, CDC member from Jaghatu District, December 3, 2016. 
Respondents in four of the seven districts told enumerators that the Taliban and other opposition groups such as Hezb-i-Islami were primarily responsible for resolving disputes in their communities.

\section{Bridging CDCs and the State}

We found limited evidence that the CDCs serve a bridging function between villages and higher state institutions. In theory, the establishment of CDCs would have provided government line ministries and NGOs with a community-level body through which service provision could be administered and organized. The evidence collected here suggests that this has only taken place to a limited extent.

In Jalrez, Behsud II, Maydan Shah, and Syad Abad, CDC members interviewed reported that they have not worked with any government department to deliver services. In Nerkh and Jaghatu, CDC members reported that they had worked with government line ministries in the past, but that this has now stopped due to the worsening security situation. Only in one of the villages, Behsud I, did CDC members report that the government was engaged with the CDCs on education and agriculture services on a periodic basis. ${ }^{46}$ Overall, it appears that the government is currently providing no services in these communities through the CDCs, aside from technical support for agriculture and education in Behsud I. ${ }^{47}$

On the contrary, in many of these communities, both NGOs and government officials are largely absent. Rather than viewing the CDCs as aligned with the government, CDC officials and community members generally view CDCs as a separate body entirely. Interviewees in the more insecure districts had few positive things to say about their interactions with government institutions. In Sayd Abad, the CDC head himself spoke contemptuously of the government: "In fact, government officials cannot get out of Kabul, so how could they come here? They have made towers for themselves in Kabul

46. Interview, CDC member from Behsud I, December 4, 2016.

47. This finding was contested by interviewees at the central and district level who had worked on the NSP in Wardak. They reported that CDCs regularly lobby the government and NGOs to attract funding for further projects, and that more than Io\% of CDCs in Hesa-e Awal Behsud, Markaz Behsud, and Jalrez have succeeded in finding this funding. However, community members and CDC officials interviewed in these areas did not substantiate this claim. 
to hide behind. Security is bad, and no one can come here." ${ }^{48}$ The CDC head in Maydan Shah claimed to have contact with NSP officials but no others, and expressed similar frustrations with the government: "We don't want to keep relations with the military-we are tired of them. To provide projects and serve the people is good, but they put innocent people in prison... [which] increases the distance between the government and the people." ${ }^{49}$ The head of the CDC in Jaghatu went further, claiming that they were no longer registered with the government and had no contact with NGOs either: "We are only CDCs in name."50

Overall, the evidence suggests that in the areas where they are able to operate, CDCs have not become the preeminent source of local governance in Wardak. There are few indications that the government is using them as a conduit for the work of central line ministries, nor do they provide a link to the central government for the majority of communities interviewed, with the exception of Behsud I. CDC members interviewed did not appear to see themselves as affiliated or accountable to government institutions; on the contrary, they saw themselves strictly as local representatives of their villages, and were often highly critical of the government.

\section{Participatory Governance through CDCs}

One of the broader objectives of the NSP was to improve representation and inclusiveness in local governance by making CDCs fully participatory, with quotas for traditionally marginalized groups. CDC members were elected through local democratic elections facilitated by NGOs, in which every member of the community had one vote. As noted, NSP guidelines stipulate that women should be equally represented on the local councils.

Respondents confirmed that CDC elections had indeed occurred in their communities, and generally felt themselves to be adequately represented. "The CDC is accountable to the people and they do everything for the people in this area.... [The benefiting of some groups over others] has not taken place in this area," stated one laborer from Behsud II. ${ }^{51}$ Another community member from Jalrez agreed, stating: "I want to say, as an individual in the

\footnotetext{
48. Interview, CDC head from Sayd Abad, December 4, 2016.

49. Interview, CDC head in Maydan Shah, December 6, 2016.

5o. Interview, CDC head from Jaghatu, December 3, 2016.

5I. Interview, laborer from Behsud II District, December 5, 2016.
} 
community, that the CDC does its work very transparently." ${ }^{22}$ Respondents were unanimously content with the electoral system used to select CDC members, and we uncovered no complaints that the election process was perceived as rigged or unfair.

However, the communities profiled in Wardak performed poorly in ensuring equal female participation. Of the seven CDCs profiled, respondents in five-Jaghatu, Jalrez, Maydan Shah, Nerkh, and Sayd Abad—unanimously reported that no women had ever served on their CDC. Both male and female respondents in these areas expressed belief that women in their communities were not educated enough to participate as CDC members and that it was inappropriate for them to do so. The findings suggest that particularly in the Pashtun-majority areas of Wardak, the NSP has not been successful in securing female participation in local governance. In these areas, the establishment of female participation in CDCs is extremely challenging, given the mixture of conservative cultural attitudes, low levels of female education, and a high level of insecurity in these districts, exacerbated by the presence of Taliban forces.

In contrast, in Behsud I and II, the two Hazara-majority districts in the northwest of the province, CDCs included female members. However, attitudes to female participation differed between men and women. Female respondents interviewed in these areas commended the NSP for mandating female participation. They felt it was meaningful, and that female CDC members had some influence on determining local priorities. However, the perception of male community members was somewhat different. In Behsud I and II, male community members described the significance of female participation in the CDC as very limited. Despite efforts by the NSP to promote the benefits of gender equality, the perceptions of male interviewees regarding female CDC members remains highly influenced by traditional beliefs about the appropriate roles of women. "There are women in our CDC," said one male CDC member in Behsud I, "but as the women don't have enough education, they can't do anything." ${ }^{53}$ A community member from the same village agreed: "The women are not educated, they are like blind people. The men do everything [in the CDCs]." ${ }^{54}$

52. Interview, driver from Jalrez District, December 8, 2016.

53. Interview, CDC member from Behsud I District, December 5, 2016.

54. Interview, farmer from Behsud I District, December 5, 2016. 


\section{Insecurity and the Sustainability of the CDCs}

While we could not reach communities in the most insecure areas of the province, NSP employees estimated that a substantial number of CDCs in remote, Taliban-controlled areas of Jaghatu, Nerkh, Sayd Abad, and Maydan Shah have ceased to function meaningfully. Generally, these CDCs were located in the villages farthest from the district centers.

In the communities we could reach, we found that council members coped with mounting insecurity in a number of ways. First, although all communities nominally had CDCs, five of the seven councils, all located in relatively insecure areas, had become functionally inactive. Interviewees commonly mentioned two main reasons for this. In Sayd Abad, respondents mentioned that CDCs were specifically targeted by insurgent groups as part of their campaign against the government. CDC members reported that they were warned to stop their work by the Taliban, and that they were afraid of being associated with the CDC. This fear was also shared by community members, impeding the ability of CDCs to play a leadership role: "We don't approach [CDC members] because it is a security threat for us," said one housewife in Sayd Abad. ${ }^{55}$ A more commonly mentioned reason in other communities was that, as insecurity rose, government agencies and NGOs withdrew from the area, and there were no projects to implement and therefore no reason for CDCs to continue with meetings. Respondents in the more insecure districts blamed the lack of projects on poor security conditions, and repeatedly stated that the government should be focused on improving security over all other priorities. "The NSP should start first with security, because without security nothing can be done in our area," said one respondent from Nerkh. ${ }^{56}$ Another CDC member, from Sayd Abad, agreed: "We need security more than financial support; if there is security in our area there will be a lot of work opportunities.... In the past, our projects were interrupted because of fighting in the area." 57

When asked how CDCs had continued to operate in the presence of insurgent forces when the NSP was active, interviewees in four of the seven villages explained that their councils actively collaborated with insurgent forces and continue to do so. For example, community members in Nerkh 
explained that the Taliban and Hezb-i-Islami dominate village politics, with the latter operating checkpoints in the immediate vicinity of the village and the former operating checkpoints nearby. According to respondents, these two groups are the most important local political actors and can influence how resources are spent, including NGO funding. Similarly, multiple respondents in Jaghatu openly stated that their CDC members (who were also the traditional village elders) were cooperating with Taliban forces, and that Taliban insurgents played an active role in village politics. By contrast, the government had little to no presence or influence. While CDCs may continue playing a development role under these circumstances, they are clearly not functioning as a mechanism for furthering government legitimacy or transforming local politics in the manner intended by the NSP's planners. Instead, these dynamics demonstrate the weakness of institutional logics in the context of armed politics and the resilience of customary forms of authority at the village level. Under these conditions, CDC members see themselves, and behave, not as agents of the state but primarily as representatives of their local communities, with few upward ties and little accountability.

\section{DISCUSSION AND CONCLUSION}

This study assesses the extent to which the NSP has achieved its developmental and institutional goals in Wardak Province. From a developmental point of view, the NSP has succeeded in improving access to infrastructure and services for people in the targeted communities, which has brought tangible economic benefits in the villages profiled. Although we find that these benefits are not necessarily enjoyed equally by every member of the community, there are more people who have access to infrastructure and services than prior to the NSP. Though our conclusions are limited to the villages included in the study, they are consistent with other evaluations in Afghanistan and elsewhere that have documented improvements in basic infrastructure and public welfare as a result of CDD programs. However, we did not find much evidence for the success of the NSP's broader institutional goals, either in terms of expanding their mandate beyond developmental activities or in bridging local communities and state institutions. Participation in CDCs generally reflected local norms, with more-conservative areas refusing to comply with mandates for female representation. 
The findings offer a number of important theoretical and practical insights. First, the findings challenge theoretical assumptions linking CDD programs to transformational models of statebuilding. While local councils established under the NSP performed reasonably well at their primary mandate of delivering development projects, there is scant evidence that their remits ever expanded, or that local community members ever saw them as anything more than an institution to oversee the dispersion of aid. Furthermore, we observed that CDC members did not necessarily see themselves as affiliated with the state, and community members often differentiated between government institutions and CDCs. These findings cast doubt on whether CDD programs alone can work as an effective device to further government legitimacy and thus function as an effective counterinsurgency tool. It is notable that CDC members who were highly critical of the government and expressed a desire to cut ties with it still praised the NSP and signaled a willingness to continue accepting aid funds, indicating that active participation in the NSP is a poor proxy for popular sentiment about the government as a whole.

Another insight of this study is that many of the developmental gains of the NSP appear to be fleeting. While much of the infrastructure created under the NSP is still intact, there is a distinct lack of clarity about the sustainability and long-term maintenance of this infrastructure. A few projects we found required considerable maintenance or had fallen into disrepair. This is particularly the case in more insecure districts, where development projects have mostly ceased and government activities are almost completely absent. This finding has methodological implications for how CDD programs are evaluated. Most evaluations are completed shortly after the completion of the program and rarely set aside funds to evaluate mediumor long-term effects. But the findings raise questions about the durability of both developmental outcomes and institutional achievements in the long term. Furthermore, setting expectations for the provision of public goods without a sustainable plan to maintain them may have the ultimate effect of creating distrust of the government if those goods ultimately fail. Future evaluations should seek to measure impact over a longer period, particularly in violent contexts where government control is constantly in flux.

In terms of theoretical contributions, this study concurs with other evidence that CDDs can serve as a relatively effective mechanism for development spending, even in areas beset by insurgency. However, it is increasingly 
questionable whether a CDD program like this, highly dependent on the distribution of aid, can genuinely function as a mechanism for expanding state authority in highly insecure areas. The evidence presented here suggests that the underlying institutional assumptions are too ambitious, at least within a limited timeframe. While public goods delivery may weakly, temporarily translate into higher trust in government institutions, we found that opinions about the government were more strongly determined by other issues, chiefly local interactions with security forces and the perceived ability of the government to keep local communities safe.

Theoretical frameworks in violent contexts should therefore take into account that there appears to be a hierarchy of public goods in terms of fostering state-society relations, with security and well-functioning mechanisms for dispute resolution given a higher priority than infrastructure and other public services. We suggest that institutional theoretical frameworks include more specific outcomes on governance, with more clarity on how success in this domain can be measured. Practically speaking, implementers should seek to integrate CDD programs within sustainable frameworks for public service delivery, while downgrading expectations about their potential for institutional transformation in highly insecure contexts. 